\title{
Del ius gentium al derecho globalizado: una reflexión sistemática a partir de principia iuris permite la construcción de una categoría de 'obligación' sustancialmente humana
}

\author{
Do ius gentium ao direito globalizado: uma reflexão sistemática a partir de principia \\ iuris permite a construção de uma categoria de 'obrigação' substancialmente \\ humana
}

\section{From ius gentium to globalized law: a reflection based on principia iuris allows the construction of a category of substantially human 'obligation'}

Martha Lucía Neme Villarreal ${ }^{*}$

\section{Resumen}

La globalización impone la construcción de una teoría de la justicia universalizable sobre la base de un sistema abierto de fuentes, en la que los principios constituyen elemento de consenso en el nuevo paradigma de los sistemas abiertos a los que nos avoca la globalización. En este contexto el derecho romano se erige en modelo de armonización del derecho en cuanto construyó un derecho con vocación universal, el ius gentium, fundado en la fuerza persuasiva de sus principia iuris, cuya extendida aceptación lo erige en patrimonio común de la humanidad. El método de razonar de los juristas romanos dota al jurista contemporáneo de los elementos necesarios para resolver las vicisitudes de las relaciones de un mundo globalizado, en cuanto promueve una visión sistemática que refuerza la coherencia y hace imperioso el consenso en torno a las categorías ordenadoras del sistema, en una visión en la que los derechos nacionales codificados dan paso a principios y a las reglas que desarrollan los valores ínsitos en los principia iuris. Lo cual le impone al jurista un rol de mayor exigencia, en cuanto lo convierte en un permanente "reconstructor de las fuentes" tarea que lo conmina a la elaboración de criterios mediante el entendimiento de las estructuras que subyacen al sistema. Como un ejemplo paradigmático, la herencia común del derecho romano en materia del concepto de 'obligación' se erige en elemento de armonización en el marco de la globalización, que nos otorga argumentos para construir una categoría que refleje una concepción de la misma fundada en la humanitas.

Palabras clave: Globalización. Derecho romano. Principios. Obligación. Humanitas. Sistema abierto de fuentes del derecho. Diálogo de las fuentes. Positivismo jurídico.

\section{Resumo}

A globalização impõe a construção de uma teoria da justiça universalizável sobre a base de um sistema aberto de fontes, na qual os princípios constituem elemento de consenso no novo paradigma dos sistemas abertos aos quais nos avoca a globalização. Nesse contexto, o direito romano se erige em modelo de harmonização do direito, uma vez que construiu um direito com vocação universal, o ius gentium, fundado na força persuasiva de seus principia iuris, cuja estendida aceitação o alça a patrimônio comum da humanidade. O método de raciocinar dos juristas romanos dota o jurista contemporâneo dos elementos necessários para resolver as vicissitudes das relações de um mundo globalizado, por promover uma visão sistemática que reforça a coerência e torna imperioso o consenso em torno das categorias ordenadoras do sistema, em uma visão na qual os direitos nacionais codificados dão lugar a princípios e regras que desenvolvem os valores ínsitos nos principia iuris. Isto impõe ao jurista um rol de maior exigência, uma vez que o converte em um permanente "reconstrutor de fontes", tarefa que o conclama à elaboração de critérios mediante o entendimento das estruturas que subjazem ao sistema. Como um exemplo paradigmático, a herança comum do direito romano, em matéria do conceito de 'obrigação', alça-se a elemento de harmonização no marco da globalização, que nos outorga argumentos para construir uma categoria que reflete uma concepção fundada na humanitas.

Palavras-chave: Globalização. Direito romano. Princípios. Obrigação. Humanitas. Positivismo jurídico.

\footnotetext{
Doctora en derecho y Magister de la Universidad de Roma TorVergata. Profesora titular Universidad Externado de Colombia. Bogotá - Colômbia. E-mail: nemevilla@hotmail.com.
} 


\section{Abstract}

Globalization imposes the construction of a universalizable theory of justice on the basis of an open source system, in which the principles constitute a consensus element in the new paradigm of the open systems to which globalization leads us. In this context, Roman Law stands as a model for the harmonization of law, as it built a Law with universal vocation, the ius gentim, founded on the persuasive force of its principia iuris, whose widespread acceptance makes it the common heritage of humanity. The Roman jurists' method of reasoning endows the contemporary jurist with the elements necessary to solve the vicissitudes of the relations of a globalized world, insofar as it promotes a systematic view that reinforces coherence and makes consensus about the ordering categories of the system, in a vision in which the codified national Laws give way to principles and rules that develop the values embedded in the principia iuris. This imposes on the jurist a more demanding role, since it makes him a permanent "reconstructor of the sources", a task that leads him to the elaboration of criteria through the understanding of the structures that underlie the system. As a paradigmatic example, the common legacy of Roman law in the concept of "obligation" is an element of harmonization in the context of globalization, which gives us arguments to construct a category that reflects a conception of it based on the humanitas.

Keywords: Globalization. Roman Law. Principles. Obligation. Humanitas. Open system of sources of law. Dialogue of sources. Legal positivism.

\section{Introducción}

La globalización de la economía, de la información, de los recursos naturales, de los servicios, de los riesgos, entre muchos otros aspectos, exige implementar un modelo de "teoría de la justicia" que revalorice los conceptos de sociedad civil y Estado, en el marco de la comprensión de que la regulación de las nuevas relaciones entre ciudadanos del mundo globalizado sólo son posibles a partir de la construcción de sistemas jurídicos abiertos, que superen los estrechos confines de los tradicionales sistemas cerrados, ligados al territorio interno y a los contextos meramente locales (VECA, 1999, p. 142-143).

En efecto, "el pluralismo de valores" constituye el sustrato que cimienta la globalización, ${ }^{1}$ en el ámbito de relaciones que trascurren frecuentemente sin sujeción al territorio estatal y que dan lugar al nacimiento de un nuevo derecho, cuyas reglas se tejen con independencia de la soberanía nacional (ZAGREBELSKY, 1992, p. 7 e ss.). ${ }^{2}$ Esta circulación de ideas comunes se refleja en la praxis de los negocios que traspasan las fronteras nacionales y con ellas las pretensiones de soberanía, para exigir de retorno una comunidad de fuentes del derecho que entre a ocupar el lugar de las codificaciones nacionales, dado que el nuevo orden jurídico, este renovado ius Gentium, que propone la globalización no puede sustentarse en el modelo de los códigos formulados con pretensiones de plenitud y sobre la base de derechos nacionales.

Ciertamente, los sistemas cerrados, sustentados en una estricta tridivisión de poderes que legítima de manera exclusiva al legislador como fuente de creación normativa, conducen a la rigidez del sistema jurídico y entraban enormemente la "fluidez del sistema de fuentes", ${ }^{3}$ necesaria en un modelo que propugne por la más flexible regulación de las relaciones jurídicas en un mundo globalizado. Esta división de poderes estuvo presente en la época post- clásica del mundo romano, inspirada en la ideología justineanea, por virtud de la cual se pretendió reservar al emperador la función legislativa, limitando al juez a una mera

De "sociedad pluralista", como verdadero signo distintivo del constitucionalismo moderno habla E. Cortés (2007, p. 161-162).

A este respecto se habla de la 'crisis del Estado Nacional' como consecuencia de la propia estructura de los ordenamientos nacionales que no se funda en la 'validez universal', sino en el desueto principio de territorialidad. Véase al respecto Mariateresa Cerullare (2009, p. 31).

Como lo señala Edgar Cortés (2007, p. 165-166), quien afirma que por sistema cerrado ha sido definido aquel sistema "de creación normativa o si se quiere de fuentes, - que- se inspira en el principio de la tridivisión de los poderes propio de la ilustración, en donde además de un poder (el ejecutivo) que ve por el desarrollo de la comunidad, y de un poder (el judicial) que debe identificar y aplicar las normas, existe un poder (el legislativo) que las crea, es decir, existe un órgano predispuesto que tiene la legitimación expresa para la creación del derecho; un órgano que es fuente de normas y que en desarrollo de su función valora libremente los intereses en juego dentro del grupo social”, a la vez que agrega que se entiende por " 'sistema abierto', cuyo ejemplo paradigmático es el derecho romano clásico, aquel en cual se le da menor importancia a los datos normativos expresos, dictados, de tal manera que el órgano encargado de determinar en última instancia el derecho aplicable, el jurisprudente en el derecho romano, pueda ir más allá de los juicios de valor que ya han sido reconocidos, o de la disciplina identificada y aplicada para un caso concreto, con la posibilidad de introducir así innovaciones respecto del derecho anterior y que se encuentra en uso". 
función de aplicador de la ley "con los consecuentes problemas de desconocer la imposibilidad de trazar una neta división ente las dos labores, en cuanto la labor de aplicación del derecho implica la interpretación y con ella viene la producción del derecho" (GALLO, 2004, p. 5).

Ahora bien, en el mundo contemporáneo la complejidad de las relaciones jurídicas que surgen en el contexto internacional, aquella de nuestros propios ordenamientos jurídicos, la creciente interacción entre los cuerpos legales que regulan diversas materias, la necesidad de referir toda interpretación de la ley a los valores adoptados por la constitución política y por los tratados y principios que con vocación universal ${ }^{4}$ integran nuestras cartas fundamentales, en el marco del complejo axiológico que caracteriza el sistema jurídico del que participan nuestros ordenamientos, ${ }^{5}$ evidencian de manera innegable el carácter abierto de los mismos, ${ }^{6}$ lo que refleja un cambio de paradigma, que nos lleva no sólo del "Estado de derecho" a la "edad de los derechos", evocando a Bobbio (1990), y "del tiempo de los códigos a aquél de las constituciones", siguiendo a Rodotà (2012, p. 41 e ss.), sino que pone de manifiesto la necesidad de encontrar un lenguaje común suficientemente sólido, pero también flexible que tenga la fuerza de regir las relaciones que surgen en el contexto transnacional.

El punto central de este nuevo paradigma, sostiene este último, lo constituye la dimensión de la garantía y desarrollo de los derechos fundamentales, en una renovada forma de ser de los estados democráticos que transitan, mediante sus constituciones, de la legislación detallada a aquella de los principios, como recurso de coherencia y garantía de igualdad "en un mutado sistema de fuentes" (RODOTÀ, 2012, p. 41$54)^{7}$

Este sistema abiertos de fuentes no es en verdad una novedad, pues ya los juristas romanos entendían el ius como mecanismo para asegurar la convivencia social, de ahí que su finalidad última eran los casos concretos a la luz de las exigencias de la realidad, por lo que las normas ocupaban un papel

Sobre universalismo jurídico y, en particular, sobre la validez universal del iusromanum "en relación con todos los hombres y todos los pueblos" (Tanta 23), consúltese el escrito de CELLURALE, M., "Locus e ius", observaciones sobre espacio y sistema a la luz del derecho romano, en Revista de Derecho Privado, Universidad Externado de Colombia, Bogotá, vol. 16, p. 31 y ss. Consultable en línea en: < www.uexternado.edu.co/ derechoprivado>.

5 Véase el trabajo de la profesora Catalina Salgado (2013, p. 203-204) sobre la interacción entre ordenamiento y sistema en el que sostiene que “el reconocimiento de una perspectiva de sistema tiene como virtud liberar al jurista del 'ensimismamiento' de frente a una 'laguna' y llevarlo a encontrar la solución aplicable sirviéndose del diálogo, de la interacción con el sistema jurídico sobre el que se sienta su ordenamiento, atendiendo a lo que mencionamos como dimensionesestática y dinámica del sistema, entendidas en función de la noción de principiumcomún: estática que implica un estudio juicioso de las fuentes y de las elaboraciones sucesivas (en su contexto), que por contra lleva al jurista a un mayor entendimiento de las categorías dogmáticas actuales y a retomar las problemáticas a partir de categorías fundamentales; dinámica: que tiende al hombre en su devenir constante y al derecho como reconocedor de las nuevas circunstancias, capaz de reelaborarse; que reconoce en la codificación un momento de llegada, producto de la elaboración científica, pero que al mismo tiempo no cierra las compuertas a un ulterior enriquecimiento que responda a una posición activa por parte del jurista; que en últimas no condena al juez al solo uso del instrumento de la analogía (legis)": Sobre el mismo tema véase también Schipani, S. (2007, p. 5 y ss).

6 Este carácter de abierto de las codificaciones fue puesto de relieve por Miguel Reale (2017), refiriéndose al proyecto de Código que se adoptara como Código Civil del Brasil en 2002: "Lo que importa en una codificación es su espíritu; es un conjunto de ideas fundamentales en torno a las cuales las normas se entrelazan, se ordenan y se sistematizan. En nuestro proyecto no prevalece la creencia de la plenitud hermenéutica del derecho positivo, se reconoce el imprescindible carácter ético del ordenamiento. Un código es un sistema, un conjunto armónico de preceptos que exige a todo instante recurso a la analogía y a los principios generales [...]" Carácter de abierto que reconocen expresamente gran parte de los ordenamientos jurídicos civiles latinoamericanos, en los que se hace expresa remisión a los principios generales del derecho para resolver los problemas de interpretación de la ley y llenar sus lagunas. En el caso colombiano desde la República de la Nueva Granada, en la que se expidió la Ley $1^{\mathrm{a}}$ de 10 de mayo de 1834, que en su artículo 125 dispuso que para resolver los asuntos litigiosos los jueces, en defecto, insuficiencia $u$ oscuridad de la ley deberían decidir "por fundamentos tomados del derecho natural, de la justicia universal i de la razón", posteriormente el Código Civil del Magdalena -Ley de 17 de diciembre de 1857- dispuso: "IV. La costumbre no tiene fuerza de lei en ningún caso. A falta de lei o cuando esta sea oscura o deficiente, los tribunales y juzgados apoyarán sus decisiones en los principios de la justicia universal y de la razón", a su turno la Ley 153 de 1887 señaló en su artículo $8^{\circ}$ "Cuando no hay ley exactamente aplicable al caso controvertido, se aplicarán las leyes que regulen casos ó materias semejantes, y en su defecto, la doctrina constitucional y las reglas generales de derecho", precepto que quedó incorporado en la Constitución Política de 1991 en su artículo 230.

Ello, según el autor, "debido a la multiplicidad de los sujetos nacionales, supranacionales e internacionales que incesantemente producen reglas: - a la - mutada cualidad de las reglas jurídicas, analítica o de principio, hard o soft, dura o flexible; puesta en duda la legitimidad de la regla jurídica de invadir todo momento de la vida y, así mismo, redimensionado el propio poder del legislador; generalizado el control sobre la constitucionalidad de las leyes; crecida la necesaria flexibilidad del sistema jurídico para afrontar las múltiples dinámicas que continuamente transforman la sociedad". 
instrumental y debían ser adecuadas al caso ${ }^{8}$ en miras de lograr el fin último del derecho: la realización del bonum et aequum en la resolución de los casos; una tal concepción del ius sólo podía partir de la conciencia de que su ordenamiento no era completo $^{9} \mathrm{y}$, por ende, estaba conformado por un sistema abierto de fuentes, ${ }^{10}$ entre ellos el iusdicere del pretor, mediante el cual se colmaban las deficiencias y se eliminaban las desviaciones de las normas existentes, ${ }^{11}$ evidenciadas en la aplicación al caso concreto (GALLO, 2004, p. 7-8).

Ahora bien, este sistema abierto de fuentes comienza a restringirse a la par que se entronizan formas de poder más absoluto, que pretenden asegurar para sí 'el control político de la jurisprudencia', ${ }^{12}$ al cual, evidentemente, se opone la globalización del derecho.

De ahí que con miras a la construcción de un derecho globalizado, debemos considerar las enseñanzas del derecho romano; ya lo decía Gallo (2004, p. 11) respecto del derecho europeo, al resaltar la necesidad de superar la concepción positivista del derecho para develar su esencia en el bonum et aequum ${ }^{13}$ y su verdadera naturaleza en el hecho de que este constituye un ars, ${ }^{14}$ con lo que se pone en evidencia que la producción, interpretación y aplicación del ius exige que los juristas se vuelvan a

8 D. 50.17.1: "PAULO; Comentarios a Plaucio, libro XIII.- Regla es la que expone brevemente la cosa, tal cual es. El derecho no se toma de la regla, sino, que la regla se hace con arreglo al derecho que hay. Así, pues, por medio de una regla se hace breve narración de las cosas, y como dice Sabino, es como un compendio de la causa, que tan pronto como es viciada en algo, pierde su eficacia".

9 Catón en Cicerón. de Rep. 2.2 -3: "decía de hecho Catón que nunca hubo un ingenio tan alto al que nada pudiese escapar, y que tampoco tantos ingenios juntos, sin la esperanza que deriva del transcurrir del tiempo, podrían en un solo momento histórico prever todo y a todo proveer"; $\mathbf{D}$. 1.3.10 -12: "10. Juliano; Digesto, libro LIX.- Ni las leyes, ni los senadoconsultos pueden escribirse de modo, que se comprendan todos los casos que de vez en cuando ocurren, sino que basta que se contengan los que ordinariamente acontecen.11. El mismo; Digesto, libro XC .- Y por lo tanto, respecto de aquellas que primeramente se hallan establecidas, se ha de determinar con más certeza o por la interpretación, o por constitución del óptimo Príncipe. 12. El mismo; Digesto, libro XV.- No pueden comprenderse en las leyes o en los senadoconsultos determinadamente todos los casos; pero cuando en alguna ocasión esté manifiesto su sentido, debe el que ejerce jurisdicción proceder por analogía, y de este modo proferir sentencia"; D. 1.3.32. pr. "Juliano; Digesto, libro XCIV .- En aquellos casos que no usamos de leyes escritas, conviene se guarde lo que el uso y la costumbre se ha introducido; y si esto faltare en algún caso, entonces lo que le sea análogo y consiguiente; y si en realidad tampoco apareciere esto, entonces debe observarse el derecho que se usa en Roma".

10 El sistema abierto de fuentes del derecho romano se pone de presente en la definición que por vía de partición efectúa Cicerón de los elementos que confluyen en el proceso de formación del ius, con prescindencia de su valor vinculante. Dice Cicerón en tópica 5.28: "el iuscivile es aquello que consiste en las leyes, en los senados consultos, en las sentencias, en la autoridad de los juristas, en los edictos de los magistrados, en la costumbre y en la equidad" (VACCA, 2012, p. 26).

11 D. 1.2.2.12: "De esta suerte, en nuestra ciudad se determina o por derecho, esto es, por ley, o hay derecho civil propio, que sin estar escrito consiste en la sola interpretación de los jurisconsultos; o hay acciones de la ley, que contienen la forma de proceder; o plebiscitos, que se establecieron sin la autoridad de los patricios; o edicto de los magistrados, de donde nace el derecho honorario; o senadoconsultos, que sin ser ley se establece constituyéndolo solamente el Senado; o constitución del príncipe, esto es, lo que el mismo príncipe determina que se observe como ley".

12 Así, entre las fuentes del derecho, según lo describen las Instituciones de Gayo: Inst. Gayo 1.2 "se encuentra en las leyes, en los plebiscitos, en los senadoconsultos, en las constituciones de los Príncipes, en los edictos de los que gozan del poder de promulgarlos y en los dictámenes de los jurisconsultos. [...] 7.- Los dictámenes de los jurisconsultos son los pareceres y opiniones de aquellos a quienes les está permitido fijar el Derecho.". Este elenco de las fuentes traído por Gayo en el principado (segunda mitad del II sigo D. C.), se diferencia notoriamente de aquél expuesto por Cicerón en los Tópicos: respecto de la edad republicana, faltan las re iudicate, el mosy la aequitas y no se habla más de la autoritas de los juristas en general sino de los responsos de aquellos juristas a los cuales se les ha concedido la facultad de formular el derecho, el 'Iusrespondendi ex autoritateprincipis', con lo que se elimina la interpretación de los juristas del cuadro de las fuentes del derecho so pretexto de reforzarla con la autoridad del poder imperial, lo que conduce a la pérdida de la independencia y autonomía de los juristas, mientras en cambio, entre las fuentes, aparecen las constituciones imperiales. De manera que en el principado se evidencia una concentración de los poderes en manos del príncipe a la vez que se produce una pérdida de autonomía y eficacia real de los poderes normativos de los demás órganos como los comicios, el senado y los magistrados investidos del poder de decir el derecho, proceso que tendrá su momento culmine en el dominado, en donde el emperador será el único intérprete y legislador. Cfr. Letizia Vacca. La giurisprudenza nel sistema delle fonti del diritto romano. Corso di lezione. Segunda edición. Torino: Giappichelli, 2012, p. 75, 82-83.

13 Binomio que en términos modernos expresa, según la reconstrucción de Gallo, la razonabilidad e igualdad proporcional .Y en el que el aequumno significa justicia, en términos abstractos, sino igualdad en el sentido elástico de proporcionalidad. CFr. F. Gallo. Sulla definizione Celsina del diritto. En SDHI, 53 (1987), p. 7 y ss.

14 Refiriéndose a la definición celsina de iuscontenida en D. 1.1.1 en la que el término definido, el ius, es subsumido en el género próximo ars, término este último con el que los romanos indicaban a la vez el conjunto de conocimientos teóricos, las capacidades prácticas y las actividades necesarias para dar vida a los primeros, haciéndolos operantes por el hombre en la realidad terrena. Cfr. F. Gallo. La 'verità': valore sotteso alla definizione celsina del diritto. Ponencia presentada en las jornadas de estudio sobre valores y principios del derecho romano, en conmemoración de los cien años del profesor Silvio Romano, maestro de instituciones. Torino 12/10/2007. En: http://www.dirittoestoria.it/7/Tradizione-Romana/ Gallo-Verit-valoredefinizione-celsina-diritto.htm\#_2._Non_degradabilità a Leerformel. Consultada el 27 de mayo de 2017. 
apropiar del ars iuris del que fueron despojados por Justiniano ${ }^{15}$ y retomen la técnica romana clásica en la construcción del derecho.

\section{Los principios constituyen elemento de consenso en el nuevo paradigma de los sistemas abiertos}

Hemos sostenido precedentemente (VILLARREAL, 2014) (16 $^{16}$ que la imposibilidad de crear ordenamientos jurídicos completos y perfectos que contengan la totalidad de decisiones adecuadas a todos los $\operatorname{casos}^{17}$, las continuas perplejidades que suscita, aún en los casos reglados, la concreta aplicación de las normas jurídicas y por demás los renovados retos de encontrar soluciones con vocación universal, que satisfagan las exigencias de los disímiles intereses en juego en el contexto internacional, pone en evidencia la necesidad de acudir a los principios que orientan el ordenamiento ${ }^{18}$ y el entero sistema; principios cuya racionalidad y corrección guían la interpretación y la aplicación del derecho, dotándolo de la coherencia y de la legitimidad que genera el consenso ${ }^{19}$ de las decisiones adoptadas con fundamento en razones sustanciales, como los principios y, en cuanto tal, en términos de Perelman, decisiones que pueden ser al mismo tiempo justas y conciliables con el derecho en vigor (PERELMAN, 1979, p. 177).

15 Sobre este proceso de despojo a los juristas del ars iuris por parte de Justiniano, Filippo Gallo recuerda que en la edad republicana e imperial la producción del derecho era reconducida a la soberanía popular, bien por la lex, pues en ellas el pueblo expresaba su voluntad con el suffragiumen la asamblea popular, como por las mores en las que el propio comportamiento del pueblo creaba derecho (D. 1.3.32.1). Era la interpretatio de los juristas, su "propuesta interpretativa" de las mores la que individualizaba los comportamientos cuya reiterada repetición los convertía en derecho, pues "el derecho no se extrae directamente de las cosas o de las situaciones", de ahí que no se pueda confundir con la costumbre del derecho contemporáneo, pues en ella no se presenta esta unión entre comportamiento e interpretatio (p. 5-6, 11). Pero posteriormente la conexión entre mores e interpretatiofue rota por el emperador Adriano con la concesión del iusrespondendi exclusivamente a los juristas designados con tal facultad, así las mores fueron sustituidas por los responsa prudentium y no fue nunca más reconstituida ni siquiera con el surgimiento de la consuetudo, cual derecho no escrito, entre romanos y peregrinos, pues está última surgió siempre subordinada a la ley, mientras que las mores poseían el mismo rango, al punto que tenían la fuerza de derogar una ley (D. 3.32.1). Este proceso se acentuó con Justiniano, pues el emperador tenía la presunción de encerrar en los textos legislativos todo el saber jurídico necesario para su tiempo y todo tiempo futuro; de impedir la autónoma elaboración científica por parte de los juristas, de reservar únicamente para el emperador la actividad productiva e interpretativa del derecho, de precluir la formación consuetudinaria del mismo, de hacer a los jueces aplicadores mecánicos de las leyes ( $p .3$ y 4), de manera que con la disposición normativa que impedía la interpretatio eliminó el iuscontroversumy, el ars iuris paso a ser del dominio del emperador. No obstante ante la evidente insuficiencia de la obra compilatoria para resolver todos los casos de la realidad, en la novela 125 de 543 Justiniano concedió a los jueces la interpretatio, dándoles la posibilidad de decidir en los casos concretos según aquello que a estos pareciera justo y legítimo, con lo que los reincorporó al "circuito productivo del derecho". Filippo Gallo: Aspetti peculiari e qualificanti della produzione del diritto nell'esperienza romana. Rivista di Diritto romano IV 2004, consultable en linea en: http: //www.ledonline.it/rivistadidirittoromano/ Cfr. p. 3, 4, 5, 6, 11.

16 Neme Villarreal, M. L., Principios, cláusulas generales y estándares como orientadores del sistema jurídico, en:Estudios de Derecho Civil en Memoria de Fernando Hinestrosa. Externado de Colombia, Bogotá, 2014.

17 Con acierto sostuvo el profesor Fernando Hinestrosa (1998, p. 85) que los "ordenamientos no son completos y tampoco sus expresiones tienen un significado unívoco como valores y estático o cristalizado" y, por ende advierte que "el derecho no es solamente 'el derecho legislado'". En este mismo sentido Judith Martins Costa sostuvo, en el ámbito de la discusión que precedió la aprobación del nuevo Código Civil del Brasil, que "en un universo fragmentado de posmodernidad no tiene sentido, ni función un código total, totalizador y totalitario que, por la interconexión sistemática de reglas casuísticas, tenía la pretensión de abarcar toda la extensión de posibles actos y comportamientos debidos en la esfera privada, previendo soluciones a los diversos problemas de la vida civil en un mismo y único cuerpo normativo, armonioso y perfecto en su abstracta arquitectura" (MARTINS COSTA, 2000).

18 "En sentencia de 20 de mayo de 1936, la Corte Suprema de Justicia colombiana sentó como doctrina que las reglas generales del derecho son verdaderos principios y que éstos hacen parte del ordenamiento jurídico. En ese fallo, que acoge la doctrina de Geny y Josserand se lee que "todo el derecho no está encerrado dentro de la legalidad; alrededor de la regla formal, alrededor del derecho escrito, vive y hierve todo un mundo de principios, de directivas y de standards, en los cuales distingue muy justamente Haurioulos principios constitucionales del comercio jurídico, y como una especie de super-legalidad... Entre esas directivas pueden citarse... la regla errorcommunisfacitjus, la teoría del enriquecimiento sin causa y, sobre todo, la del abuso del derecho: aunque ningún texto de derecho positivo las enuncie en su forma general, la realidad de esos dogmas consuetudinarios es tan cierta como puede serlo la de los principios consignados en los términos más expresos e imperativos. Más aún: aquellos dogmas consuetudinarios están por encima de estos principios, puesto que escapan a la arbitrariedad del legislador, que no podría desconocer esas verdades superiores, a las cuales él mismo está subordinado, ya que no emanan de él. Los derechos que éste reglamenta no se realizan abstractamente y en el vacío: funcionan en un medio social; desempeñan un papel en ese medio, socialmente, no en una dirección cualquiera sino en vista de fines determinados; su misión es la de realizar la justicia y ellos no podrían rebelarse contra ésta sin que se incurriera en un contrasentido jurídico, en un abuso que acarrearía una sanción" (se resalta). Sent. Cas. Civ. de. G.J. XLIII, 47-48, reiterada en La sentencia de la Corte Suprema De Justicia colombiana, Sala Casación Civil, de 7 de octubre de 2009.

19 Sobre la 'capacidad de aunar sin coacciones y de generar consenso' gracias a una 'comunidad de convicciones racionalmente motivada' véanse las reflexiones de Habermas (1999, p. 27). En el ámbito colombiano consúltese López Medina (2011, p. 5) quien escribe sobre el hecho de que "la Constitución ejerce importantes funciones de cohesionamiento social" en cuanto incorpora "teorías y prácticas de justicia lo más abstractas e incluyentes posibles que buscan determinar el marco mínimo de un acuerdo social de conciudadanía" y que en cuanto goce de legitimidad "los ciudadanos han aceptado en su conjunto" y por ende logra "la coordinación social y la aplicación contundente del derecho". 
Bajo este contexto, son los principios los que tienen la potencialidad de proporcionar un criterio de correlación entre las fuentes del derecho que emanan de los diversos ordenamientos nacionales; criterio que dada la naturaleza estructural de los principios que pusiera de relieve Aristóteles, ${ }^{20}$ se encuentra dotado de una particular autoridad jerárquica ${ }^{21} e n$ cuanto reúne los valores considerados esenciales al sistema jurídico del cual abrevan. Estos valores apuntan, de nuevo, a la centralidad de la persona humana ${ }^{22}$ y a la consecuente realización de sus derechos fundamentales. Digo de nuevo, porque ya las enseñanzas antiguas nos habían alertado sobre los peligros de no tener presente que la función del derecho no era el respeto per se de la ley misma, sino la adecuada satisfacción de las necesidades humanas. ${ }^{23}$

Este fundar la coherencia del sistema en principios había sido entendido por los juristas romanos, quienes en el proceso de formación del ius, elaboraron de manera racional un conjunto de soluciones casuísticas que hizo posible coordinar las soluciones particulares con un sistema lógico y enteramente coherente pero abierto, en el sentido en que si la justicia o la equidad lo requerían el jurista podía encontrar una solución nueva (VACCA, 2012, p. 123-124).

Esta manera de construir el derecho promovía a su vez una visión sistemática que reforzaba la coherencia del ius, en cuanto las soluciones de los casos estaban fundamentadas en principios generales armónicos entre sí, así como la posibilidad del jurista de encontrar soluciones novedosas, cuando los nuevos casos no pudieran ser resueltos con las reglas y principios que habían sido individualizaos precedentemente; todo lo cual no excluía el iuscontroversum, pues la coherencia del sistema no se entendía alterada por la coexistencia de posibles soluciones diversas para solucionar un determinado caso (VACCA, 2012, p. 35), siempre que tales soluciones estuvieran cobijadas por la ratio de los principios del sistema; de suerte que los juristas romanos no sólo acudían a la fuerza persuasiva de las ratio decidendi ${ }^{24}$ identificadas en la solución de los casos precedentes, sino que este proceso estaba regido por unas exigencias de racionalidad fundada en los principios del sistema, de forma tal que excluían toda generalización que contraviniera la ratio general del ordenamiento jurídico. ${ }^{25}$

Un método de creación del ius como el romano hace imperioso el consenso en torno a las categorías ordenadoras del sistema que garanticen su coherencia y, ese papel lo desempeñan los principios, pues estos en cuanto elementos fundantes, originarios, estructurales y articuladores del sistema, son inherentes a los derechos que contienen y en cuanto tal estructuran tales derechos; operan como discursos ordenadores de las relaciones humanas y en tal virtud organizan y ordenan la sociedad al hacer posible una determinada realidad (VILLAREAL, 2014, p. 309-310), en este caso la compleja realidad de la globalización.

20 Cf. Aristóteles. Metafisica, V, 1,1013ª5-20. En donde plasma su entender de la categoría 'principio' como el primer término a partir del cual “una cosa ó es, ó es generada, ó es conocida" y destaca que en un sentido "principio significa la parte originaria e interna de la cosa y de la cual la cosa misma deriva: por ejemplo, en una nave la quilla, en una casa los fundamentos y, en los animales, según algunos el corazón, según otros el cerebro, o según otros, alguna otra parte de este tipo".

21 De "criterio de correlación al cual se confiere una autoridad" y, en tal virtud, permite la solución de conflicto de fuentes, habla Miragem, B., Eppur si muove: Diálogo das fontes como método de interpretação sistemática no direito brasileiro, en Diálogo Das Fontes. Do conflito à coordenação de normas do direito brasileiro, Revista dos Tribunais, São Paulo, 2012, p. 68.

22 Inst. lust. 1.2.12 "Todo el derecho de que usamos se refiere o a las personas, o a las cosas, o a las acciones. Tratemos primero de las personas. Porque es poco haber conocido el derecho, si se desconocen las personas por cuya causa se han constituido"; Inst. Gayo. 1.8 "Por lo demás todo el Derecho que usamos o bien trata de las personas, o bien de las cosas, o bien de las acciones. Pero consideremos primero el relativo a las personas".

23 Al respecto sostiene Vico. Principios de oratoria. §22: "las palabras sirven a las leyes, no las leyes a las palabras", de tal forma que deba entenderse que "hace fraude a la ley quien protegido por el derecho, lucha contra la razón del derecho". En nuestro ámbito, refiriéndose al sistema jurídico romano y dentro de este al subsistema latinoamericano, sostiene Chamie que "el sistema jurídico, que es un sistema de equidad y buena fe, pone en evidencia la íntima relación entre derechos fundamentales, persona humana, principios generales y progreso de la sociedad", lo cual ha de promover "un desarrollo que ubique con certeza la dignidad de la persona humana en el centro de la experiencia jurídica". (CHAMIE, 2013, p. 95)

24 Sostiene la profesora Vacca (2012, p. 114) que en el sistema romano el jurista sugiere las soluciones sin que las mismas posean en ningún momento histórico un valor preceptivo, ni siquiera para el caso en particular respecto del cual fueron emitidas. No obstante, resulta indiscutible que si se miran las fuentes de producción del derecho, no como modo de producción de reglas vinculantes, sino como procedimientos técnicos idóneos a desarrollar y, donde fuera necesario, a cambiar el ordenamiento jurídico y los criterios de solución de las controversias individuales, la actividad del jurista es un verdadero procedimiento de formación e interpretación del derecho.

25 D. 1.3.14 (Paul. 54 ad e) "Por otra parte, aquello que ha sido recibido de manera no conforme a la ratio general del ordenamiento jurídico no debe ser generalizo a otros casos". D. 1.3.15 (lul. 27 dig.) "Aquello que ha sido instituido contra la ratio general del ordenamiento no debe ser seguido como regula iuris". 


\section{El derecho romano posee una vocación de universalidad fundada en la fuerza persuasiva de sus principia iuris, cuya extendida aceptación lo erige en patrimonio común de la humanidad}

La universalidad del iusgentium ${ }^{26}$,esa vocación de aplicabilidad del ius a todos los pueblos ${ }^{27}$, basada antiguamente sobre la idea de la común pertenencia de las gentes a un sistema jurídico-religioso "supra nacional" cuyo centro es Júpiter (CATALANO, 1990, P. 44) y después sobre la naturalisratio (FIORI, 1996, p. 164), se evidencia como concepción teórico filosófica en la referencia a la societashominum, a la societasomnium inter omnes en Cicerón ${ }^{28}$, al iushumanumen Livio $^{29}$ y se expresa en deberes ético-jurídicos, cuyo origen está en las costumbres del comercio internacional en las que se inspiraba el iusgentium (ARANGIO-RUIZ, 1990, p. 206-207).

Consagrada igualmente en las Instituciones de Gayo, ${ }^{30}$ dicha concepción en la realidad se desarrollaba mediante las instituciones que formaban la base positiva del iusgentium, bien sea aquellas relativas a las relaciones con otras potencias ${ }^{31} \mathrm{o}$ aquellas destinadas a regular las relaciones entre particulares, ${ }^{32}$ entre las que resalta ese complejo de normas e instituciones destinadas a regular las relaciones entre romanos y peregrinos y entre estos últimos entre sí en el ámbito del comercio con otras ciudades.

Este nuevo complejo jurídico que integraba el ius Gentium, se aglutinaba alrededor de los principia iuris, representativos de valores vinculantes que se erigían en principios normativos, en particular aquellas instituciones forjadas a partir del oportere ex fide bona,núcleo característico del iusgentium (GROSSO, 1973, p. 440-441); principios que en cuanto estimados y reconocidos por la comunidad, como fundantes del complejo de reglas con vocación universal, se habrían paso en el nuevo escenario social: el iusgentium.

El carácter común de esos derechos, la fuerza persuasiva emana del universalismo de los principios jurídicos en que se funda la tradición romanista y, en particular, sobre la centralidad de la humanitas que los hace "válidos para todos los hombres en todos los lugares" (SCHIPANI, 2006, p. 299-300); como nos

26 Sobre este particular, retomo algunas de las ideas expuestas en mi libro: "La buena fe en el derecho romano. Extensión del deber de actuar de buena fe en materia contractual". Bogotá: Universidad Externado de Colombia, Centro di StudiGiuridiciLatinoamericaniUniversità "TorVergata" CNR Roma Italia. 2010.

27 Sobre el concepto de ius gentium, véase el estudio de Gabrio Lombardi (1947, p. 5-8), quien individualiza fundamentalmente tres acepciones que suelen darse a dicho concepto: aquella que lo define como el complejo de normas e instituciones comunes a varios pueblos en cuanto fundadas en la naturalis ratio; la que lo concibe como el complejo de normas e instituciones relativas originariamente a las relaciones entre peregrinos y ciudadanos romanos y entre peregrinos en Roma y finalmente la que lo define como el complejo de normas e instituciones relativas a las relaciones entre varios estados. Lombardi después de un análisis de las fuentes jurídicas y extrajurídicas rescata la continuidad en la concepción de ius gentium como aquellas normas e instituciones sentidas como presentes en todos los pueblos civilizados, fundadas en la naturalis ratio y en consecuencia comunes a todos los hombres, concepción esta constante desde Ciceron a Gayo. Adicionalmente, en cuanto a la polivalencia de significado que el sintagma ius Gentium asumiera en el curso del siglo Il d. C. En contraposición con el ius civile, véase el estudio de M. Talamanca (1998; p. 191 y ss).

28 Cicerón. de off. 1,17,53 en donde reconoce la existencia de tres grados de sociedad: la sociedad más amplia después de la cual no hay confines (societas hominum), aquella que consiste en la identidad de las naciones y del lenguaje (gens) y aquella más íntima todavía que es la de pertenecer a una misma ciudad (civitas); Cicerón de off. 3,17,69 en la que después de reiterar lo dicho en el párrafo precedente agrega que de ahí la razón por la que nuestros mayores reconocieran la existencia, de una parte, del ius gentium y de otra del ius civile, de donde se desprende, siguiendo la interpretación de Gabrio Lombardi del citado pasaje, que el ius gentium es el derecho de la societas omnium inter omnes y el ius civile es el derecho de la ciudad en particular, mientras que del grupo intermedio, la gens no se habla. Cf. G. Lombardi. Sul concetto di "ius gentium". Cit., p.67-72.

29 Livio 5,37,4 donde se lee “...interim Galli postquam accepere ultro honorem habitum violatoribus iuris humani elusamque legationem suam esse ..." (en el entretanto los galos habían llegado a saber que aquellos que habían violado el derecho humano habían sido incluso elegidos en una magistratura).

30 Gayo Inst. 1,1.- Todos los pueblos que se rigen por leyes y costumbres utilizan en parte su propio Derecho y en parte el que es común a todos los hombres; de esta manera el Derecho que un pueblo cualquiera establece para sí resulta propio del mismo y es llamado Derecho civil, como si dijéramos el Derecho propio de aquella ciudadanía; en cambio, el que la razón natural establece entre todos los hombres, se se observa con carácter general por todos los pueblos y es llamado Derecho de gentes, es decir, como si fuese el Derecho que utiliza todo el mundo. Y así el pueblo romano utiliza en parte su propio Derecho y en parte el que es común a todos los hombres.

31 Sobre el particular véase el ya citado estudio de P. Catalano en el que se plantea la existencia de una voluntad política de los romanos tendiente a la formación de una sociedad universal en las relaciones con los pueblos extranjeros, en el que se destacan instituciones concretas como el ius fetiale, la evocatio, la inmunidad de los embajadores, entre otros Cf. P. Catalano. Diritto e persone. Cit., p. 5-50.

32 En relación con las instituciones que en concreto conformaban el ius getium véanse a titulo de ejemplo D. 48,22,15: "Marciano.- El deportado pierde la ciudadanía, no la libertad,y ciertamente no disfruta del derecho especial de la ciudadanía, sino que se sirve del derecho de gentes; porque compra y vende, da y toma en arrendamiento, permuta hace préstamos a interés, y otras cosas semejantes ..." y D.2,14,7. Ulpiano; Comentarios al Edicto, libro IV .- En donde se efectúa una larga enumeración de las convenciones del derecho de gentes que dan lugar a acción y aquellas que dan lugar a excepción. 
lo recuerda un pasaje de Hermogeniano que dice que "todo el derecho está constituido a causa de los hombres". ${ }^{33}$

Humanitas, aequitas, fides bona, voluntas, libertas, entre otros principios romanos, constituyen no sólo legado de civilización, ${ }^{34}$ sino que se erigen en lenguaje común en el ámbito internacional, en cuanto posibilitan la flexibilidad del sistema codificado y se erigen en directrices sobre los cuales construir los nuevos consensos que requiere el mundo globalizado.

La gran aceptación de estos principia iuris y, de los valores que evocan los mismos, ha permitido no sólo su preservación al pasar de los siglos sino su adopción como propios en los múltiples países que siguen la tradición romanista ${ }^{35} \mathrm{y}$, más allá, se han convertido en puente de comunicación con otros sistemas en los procesos de armonización del derecho privado, particularmente en materia de contratos y obligaciones. ${ }^{36}$

De ahí, que es tarea del jurista contemporáneo el reconstruir (MOZOS, 1996, p. 37 ) (37 $^{37}$ este complejo de principios, reglas e instituciones comunes a los diversos pueblos a la manera del iusgentiumen cuanto fundadas en valores de nuestra tradición que han trascendido y permanecen como derecho vivo de amplio consenso entre los diversos pueblos, lo que permitirá confluir en un 'universalismo jurídico'38 fundado en los principia iuris.

\section{El método de razonar de los juristas romanos en la construcción del sistema jurídico, dota al jurista contemporáneo de los elementos necesarios para resolver las complejas vicisitudes de las relaciones de un mundo globalizado}

Un sistema abierto de fuentes, en el que los derechos nacionales codificados han de dar paso a principios y a las reglas que desarrollan los valores ínsitos en estos principia iuris, supone la necesidad de adoptar una manera de razonar renovada, así como la adopción de un proceso hermenéutico que excluya las soluciones absolutas, basadas sobre la consideración de imposición de una norma sobre otra que se estima incompatible y, por el contrario, impone criterios de coordinación que consideren la recíproca influencia que las diversas fuentes del derecho pueden llegar a realizar entre sí (ALEXY, 2005, p. 39-46).

D. 1.5.2. 2. "Hermogeniano; Epítome del derecho, libro I.- Así pues, como todo derecho haya sido constituido por causa de los hombres, trataremos primero del estado de las personas, y después de las demás cosas, siguiendo el orden del Edicto perpetuo y aplicándoles títulos adecuados y conexos, según lo permita la naturaleza de la cosa".

34 Sobre el universalismo de los principios jurídicos en que se funda la tradición romanista y en particular sobre la centralidad de la humanitas, véase el trabajo de Labruna, quien afirma que: "es necesario desenmascarar cualquier ordenamiento, cualquier "derecho", que no ponga al hombre al centro de su escala de valores. Recuperar aequitasy humanitas contra toda barbarie. Construir un derecho que sea siempre más equoy más humano, para que pueda servir al hombre, en el surco profundo de nuestra alta tradición jurídica común, que nos muestra como el derecho pueda y deba ser puesto al servicio de la humanidad y del humanismo". (LABRUNA, 2004. p. 17-32).

35 R. Zimmermann (2010, p. 208) sostiene que el reconocimiento de principios globales e instituciones jurídicas generales es ampliamente considerado como un aspecto característico de la tradición continental.

36 Sobre esta particular función de los principios romanos como armonizadores del derecho contemporáneo en materia de obligaciones y contratos véanse los trabajos de Giovanni Luchetti y Aldo Petrucci: Fondamenti di dirittocontrattuale europeo. Dalle radici romane al Draft Common Frame of Reference. Patron Editore, Bologna 2010 y Fondamenti romanistici del diritto europeo. Le obbligazione e i contratti dalle radici romane al Draft Common Frame of Reference, Patron Editore, Bologna 2010. Este último con la colaboración de Ivano Pontoriero.

37 Propone una construcción del subsistema latinoamericano a la manera en que se realizó en el derecho común, pues "la libertad de la doctrina que interpreta el corpus iuris durante el derecho común, dando lugar a un verdadero saber principial, se justifica por su fidelidad a la "tradición jurídica".

38 Sobre la necesidad de no confundir el 'universalismo jurídico' con la 'uniformidad' que elimina las diferencias y desatiende los reconocimientos recíprocos legitimados en un pretendido orden técnico económico único, impuesto por los abusivamente denominados "imperios" contemporáneos, que nada tienen que ver con el imperiumromanum, que consiste en un verdadero "orden supranacional" que une en Roma, la patria común, "una multiplicidad de civitates, de nationes, (e gentes), de populi que supera y al mismo tiempo conserva las diferencias" nos alerta Maria Teresa Cerullare (2009, p. 39). 
Este complicado proceso hermenéutico ${ }^{39}$ pone en evidencia la insuficiencia de los métodos tradicionales de interpretación ${ }^{40}$ y la consecuente necesidad de acudir a un método que permita absolver de manera adecuada las mencionadas complejidades; de ahí que se haya propuesto como alternativa el denominado "método del diálogo de las fuentes" ${ }^{41}$, que a nuestro juicio constituye no una novedad, sino más bien una renovación de la forma de razonar de los antiguos juristas romanos en la construcción del sistema jurídico.

Recuérdese que los juristas romanos eran proclives a las distinciones sutiles, a las elaboraciones jurisprudenciales de carácter eminentemente práctico, que se servían de la dialéctica (SAENZ, 2010, p. 391-392), que realizaban aplicaciones indefinidas, que a la vez que trabajaban en el reconocimiento de la existencia de un derecho consuetudinario presente en la realidad social, promovían las permanentes adaptaciones del iuscivile recibidas en los mores (GALLO, 1993, p. 16-24); que en el proceso de elaboración del ius modelaban esquemas y negocios a las nuevas finalidades que imponía la mayor complejidad de la vida, que buscaban y elaboraban definiciones, generalizaciones y reglas que conformaban un pensamiento jurídico nutrido de la gran ductilidad de la intervenciones del pretor $y$, por ende, los juristas romanos estaban siempre atentos a las exigencias de flexibilidad que requería el ordenamiento y las fuentes que operaban sobre planos diversos; todo lo cual permitió a los romanos construir un sistema jurídico sensible a las exigencias de la equidad, en consonancia con la concreta realidad de las exigencias sociales (GROSSO, 1965, p. 302).

Este tipo de pensamiento, requiere del jurista destrezas diversas, pues antes que conocimiento de las varias normatividades, o aún de los tratados internacionales, deberá estar preparado para la elaboración de "criterios con los cuales se puedan afrontar los problemas" (HINESTROSA, 2012, p. 12-13) ${ }^{42}$ y, es allí, donde el método de los juristas romanos tiene mucho que enseñarnos, pues está atento a proveer al jurista de dichos criterios, mediante el entendimiento de las estructuras que subyacen al sistema.

Los juristas romanos en el estudio de los diversos problemas proceden a individualizar las categorías en los que estos se enmarcan, reconduciéndolas a un sistema coherente de genera, de definitiones,

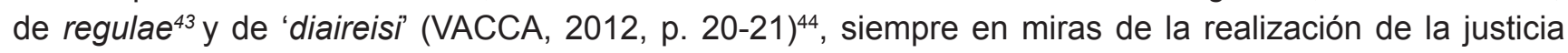
(SCHIPANI, 1987, p. 213-225); de tal suerte que la elaboración del derecho implica, como lo señala Schipani, "una combinación entre propuestas de esquemas jurídicos, valoraciones críticas de las mismas a través de las discusiones y divergencias que en sí mismas constituyen derecho (iuscontroversum),en

39 Una aproximación a esta problemática fue tratada precedentemente en M. Neme Villarreal. Pacta suntservanda y rebus sic stantibus: tensiones entre los principios de buena fe y autonomía contractual. Enero 2015. México: Universidad Panamericana. Véase la pare introductoria de este texto, cuyas ideas centrales retomamos aquí.

40 Al respecto MARQUES, C. L. (2012, p. 33) señala que "Los criterios clásicos de solución de los conflictos de leyes eran, por orden de importancia creciente: 1.- la anterioridad (la ley más nueva supera y sustituye del sistema la ley anterior en conflicto); 2.- la especialidad (una ley general nueva no deroga una ley especial antigua a no ser que la incorpore o incorpore su materia totalmente (...)); 3.- La jerarquía (una ley jerárquicamente superior, por ejemplo por su origen constitucional o una ley complementaria en relación a una ley ordinaria, una ley en relación con una ordenanza administrativa, tiene prioridad de aplicación y puede derogar una ley de jerarquía inferior en conflicto".

41 Los trabajo de Erik Jayme (1995, II p. 60 y ss.; 2003, p. 59 -68; 1997, p. 251 y ss) han promovido el uso de la expresión "diálogo de las fuentes" como método de interpretación y aplicación del derecho.

42 Por su parte, ya decía Henri Mazeaud refiriéndose al abogado que "la enseñanza superior tiene más la función de formar que de enseñar (...) formar al estudiante es prepararlo para la vida que escogió (...) prepararlo para la vida profesional, enseñarle a observar, a buscar, a exponer y a discutir". Henri Mazeaud. Métodos de trabajo. Bogotá: Universidad Externado de Colombia, 2012. p. 12-13.

43 Según señala Paulo en D. 50.17.1 (Paul. 16 ad Plautium) "La regla es aquella que describe brevemente su objeto. No es el derecho que se deduce de la regla sino es la regla la que se forma del derecho que constata. Mediante la regla se lega una breve enunciación de las cuestiones y, como dice Sabino, su estructura es similar a aquella de la 'causaeconiectio', de tal manera que si se erra en alguno de sus elementos, pierde su función". Al respecto sostiene Cannata que las reglas se obtienen por vía de un proceso de abstracción que se surte mediante inducción de la circunstancias del caso, generalizándola como una solución probable para casos futuros, que deriva su justicia de las circunstancias del caso y, por ende, la aplicabilidad de la regla a nuevos casos está sujeta a la análoga subsistencia de tales circunstancias, pues de no ser así será necesario recomenzar el proceso planteando la distinción que justifique una solución diversa. Cfr. Carlo A. Cannata, per una storia della scienza giuridica europea. Vol. 1. Dalle origini all'opera di Labeone, Torino: Giappichelli, 1997, p. 328.

44 Dalle origini all'opera di Labeone, Torino: Giappichelli, 1997, p. 328. 
una continua y fatigosa tensión hacia la construcción de un sistema coherente de aquello que es bueno y equitativo" (SCHIPANI, 2006, p. 290).

Los juristas romanos desconfían de las soluciones absolutas, están siempre dispuestos a formular nuevas reglas considerando la variedad de matices que plantea la vida en los nuevos contextos culturales (SCHIPANI, 1987, p. 253). Todo ello dentro de una manera de concebir el derecho en el que el jurista es partícipe y, no mero espectador, en la producción del derecho.

Ese proceso de creación y adaptación del ius por parte de los juristas romanos, plasmado en los responsos y cuestiones, así como en los libros de definiciones o reglas, se llevó a cabo mediante una compleja técnica que implica la explicitación de la ratio decidendi del caso previo, unida a una labor de 'distinción' de los nuevos elementos del caso que se estudia, lo cual puede conducir al planteamiento de una excepción a la regla precedentemente individualizada y, consecuentemente, a la elaboración, mediante la técnica de la abstracción, de una nueva regla o principio que se justifica en la diferencia puesta de relieve con tal distinción; regla que sirve de sustento a la decisión del nuevo caso, pero que no tiene pretensiones absolutas, sino de base argumentativa de la solución propuesta, siempre abierta a la posibilidad de ser controvertida, excepcionada, limitada o ampliada, puesto que la validez de una solución dada limita su alcance a la presencia de todos los elementos considerados como relevantes para la misma, de suerte que la aparición de una sola circunstancia diversa puede variar por completo la solución dada, esto es, la interpretatio del jurista que se erige así en el instrumento esencial en la creación del derecho, desplazando la legitimidad de la solución de todo elemento de autoridad para centrarlo en la racionalidad de la misma en conexión con el entero sistema jurídico (VACCA, 2012, p. 128-139).

En la medida en que la globalización se impone a pasos agigantados, sin dar tiempo a la consolidación de tratados o instancias internacionales que posean la suficiente legitimidad y poder de coerción, los juristas contemporáneos están llamados a tratar los problemas del ámbito internacional bajo un modelo abierto de elaboración del derecho, a la manera del derecho romano que, como vimos, le impone al jurista un rol de mayor exigencia, en cuanto lo convierte en un permanente "reconstructor de las fuentes" (CORTÉS, 2007, p. 163). ${ }^{45}$

Así, sólo la autoridad de los principia iuris, su fuerza de cohesión, su legitimidad y su poder de dotar de coherencia al entero sistema, podrán garantizar decisiones revestidas de consenso, en las que los juristas construyan soluciones que provean equilibrios transitorios dentro de un sistema en que se esté presto a revisar constantemente nuevas circunstancias, diversos matices que hagan exigible otras soluciones provisionales, en un constante devenir entre tópica y sistema, al amparo de la seguridad que otorga la preservación de los principia iuris reconstruidos permanentemente a la luz de las exigencias sociales.

Ya lo avizoraba Andrés Bello, para quien el jurista tiene por función garantizar una nueva unidad espiritual e intelectual, basado en los principios generales del derecho ${ }^{46}$ más allá de los Estados políticamente individuales, en una perspectiva social global y transnacional, que haga posible la pervivencia de los valores jurídicos de su tradición, todo ello basado en el restablecimiento de la característica fuerza de adaptación propia del derecho romano (HANNS-ALBERSTEGER, 1987, p. 181-182).

\footnotetext{
45 Cortés sostiene que en la medida en que ante "el desdibujarse de la dimensión estatal como centro de la producción normativa, esto es, la presencia al lado de la ley, en sentido estricto, de otras formas de derecho —el jurista se ve obligado — [...] más que a leer el sistema, función tradicional dentro de un esquema fundado en un código, a reconstruirlo, para ver de entender y dar un orden a la intrincada trama de hilos normativos".

46 Andrés Bello (1832) sostenía que primero se deben conocer los principios generales del derecho y pasar luego a las deducciones particulares plasmadas en los diversos ordenamientos.
} 


\section{La herencia común del derecho romano en materia del concepto de 'obligación': un elemento de armonización en el marco de la globalización que nos otorga argumentos para construir una categoría que refleje una concepción de la misma fundada en la humanitas}

Los principia iuris del derecho romano en materia de obligaciones se expresan mediante reglas como la lealtad, la diligentia, la prohibición del dolo, la protección de la parte débil (favor debitoris, beneficiumcompetenciae), la sinalagmaticidad que evoca la reciprocidad e interdependencia (exceptio inadimpleticontractus), el equilibrio (laesioenormis, rebus sic stantibus), la prohibición de abuso del derecho o de la posición de dominio, la protección de la confianza (venire contra factumproprium non valet), la cooperación, la igualdad ponderada (aequi), la solidaridad, la firmeza de los acuerdos, cuya adopción en el derecho moderno refleja un proceso de renovada consideración de los valores que subyacen en los principia iuris del derecho romano, en los que se plasman las "ideas romanas fundamentales en materia de derecho y justicia". Reglas estas, que no obstante su clara estirpe romana, no resultan del todo extrañas a otras tradiciones jurídicas

Al amparo de estas reglas y, por supuesto de los principios cuyos valores estas evocan, los juristas romanos construyeron paulatinamente un concepto de obligación que nos fuera legado y plasmado en las codificaciones latinoamericanas. En esta categoría destacan varios aspectos:

\section{A) El carácter indiscutiblemente vinculante de la relación jurídica que expresa el concepto de obligación}

El concepto de 'obligación' que se entiende como toda limitación jurídica impuesta a la voluntad, cuyo carácter esencial se encuentra en ser un "vínculo de derecho", por virtud del cual "una persona determinada se constituye en la necesidad, respecto de otra también determinada, de dar, hacer, o no hacer alguna cosa", evocando con ello el texto recogido por Justiniano, cuya autoría es remitida diversamente a Florentino o a Papiniano, conforme al cual "obligatioest iuris vinculum, quodnecessitateadstringimuralicuiussolvendaereisecundumnostraecivitasiura" (Instituciones de Justiniano 3.13. pr.).

Texto que pone de relieve el carácter indiscutiblemente vinculante de la relación jurídica que se define; carácter que probablemente retoma de las enseñanzas de Paulo quien señala que la sustancia de las obligaciones consiste en la posibilidad de constreñir al deudor al cumplimiento de la obligación (D. 44.7.3 Paulo).

De suerte que la obligación 'vincula' incluso contra la voluntad y la conveniencia del obligado y, por ello, no resulta admisible la tesis del incumplimiento eficiente basada en el concepto de obligación como 'facultad de elección'.

El carácter vinculante de la obligación se ha pretendido poner en crisis por alguna parte de la doctrina que sostiene que del contrato no derivan para las partes obligaciones de cumplimiento sino facultades de elección entre cumplimiento o resarcimiento, según la conveniencia económica que la elección comporte, tesis esta última especialmente desarrollado al interior de alguna parte de las corrientes de análisis económico del derecho, en las que se llega a plantear la eficiencia del rompimiento del contrato "efficientbreach", cuya aplicación resulta de improbable recibo dentro de un sistema jurídico que propugne valores comunes basados en la cooperación, la protección de los intereses de la otra parte, la solidaridad y la lealtad, en general .

Por demás, la confianza en la lealtad del tráfico jurídico se quebrantaría en un ordenamiento que se base en la ausencia de vinculatoriedad de la obligación.

El comercio parte de un presupuesto esencial: la confianza en la rectitud del tráfico, que se traduce en el derecho a esperar siempre el cumplimiento de la obligación pactada, el cual se trocaría por el de 
la perenne incertidumbre de esperar si a futuro el cumplimiento del contrato resultará económicamente conveniente para el deudor y, en la zozobra de tener que adquirir seguros que protejan su patrimonio ante la incertidumbre del incumplimiento o de realizar contratos alternos sobre una misma prestación, con la ilusión de aminorar el riesgo; todo lo cual desconocería la enorme transformación que significó respecto del concepto de obligación romana arcaica y clásica, el reconocimiento jurídico de la "utilidad típica de la prestación" por oposición al subrogado pecuniario.

\section{B) El carácter vinculante de la obligación (exigible en concreto frente a un sujeto específico) a diferencia del 'deber' (genérico frente a la sociedad en general) se extiende a las obligaciones que integran la relación en virtud del oportere ex fide bona}

Es justamente este carácter vinculante de la obligación lo que se erige en la diferencia substancial con la categoría de los "deberes" sociales, a los que equívocamente también se les da el nombre de obligaciones, pues el deber de respetar los derechos ajenos, no constituyen en sí obligaciones, en cuanto carecen del carácter "relativo e individual" propio de las obligaciones, mientras que, por el contrario, el respeto al derecho ajeno crea un vínculo para con todos los miembros de la sociedad.

Ahora bien, el carácter vinculante de la obligación se extiende a aquellas surgidas por virtud de la integración del contenido del contrato en razón de la buena fe (oportere ex fide bona). Claridad esta que sería hoy en día de inmenso provecho para quienes tratan de configurar una categoría que contiene en sí misma una antinomia: la de "deberes libres", para referirse a las "obligaciones" que integran el contenido del contrato más allá de las expresas previsiones de las partes o de las disposiciones legales expresas, pues también los principios son fuente generadora de obligaciones, las cuales son ciertamente verdaderas obligaciones en cuanto relativas e individuales y por ende exigibles concretamente a la persona del deudor.

La jurisprudencia colombiana, ha reiterado que los principios son fuente de obligaciones al lado de las que tradicionalmente se encuentran definidas en la ley como tales, pues habrá de distinguirse en entre derecho y ley escrita y "la ley escrita es apenas una de las fuentes formales del derecho" y, en tal sentido ha señalado que no solo las reglas positivas pueden ser transgredidas, sino que también es factible la infracción de los principios generales del Derecho, ya sea porque dejan de aplicarse, bien porque se hacen operar indebidamente, ora porque se interpretan de manera errónea. Cabe agregar que dichos principios, asimismo, tienen el carácter de normas de derecho sustancial en aquellos eventos en los cuales, por sí mismos, poseen la idoneidad para crear, modificar o extinguir relaciones jurídicas concretas (...) pues los principios hacen parte del ordenamiento jurídico.

Una tal concepción ha hecho posible derivar responsabilidad como consecuencia del incumplimiento de obligaciones que integran el contenido de la relación, aunque no estuvieran consagradas en la ley o contenidas en las obligaciones expresamente contempladas por las partes, cuando de una relación contractual se trate, haciéndose así, extensivo el carácter vinculante tanto a las obligaciones que integran la relación en virtud del oportere ex fide bona, como las derivadas de otros principios que nutren nuestra tradición jurídica.

\section{C) La posibilidad de disolver el vínculo constituye elemento esencial del concepto de obligación; si esta característica no existiera la obligación se convierte en esclavitud o en servidumbre}

En el modelo de la originaria obligación romana, "la posibilidad de la solutio es inmanente a la obligatio, en cuanto el vínculo se crea como resoluble y alude inevitablemente a un rescate". Así, en la configuración de la relación obligatoria, que se conservó en la obligatio clásica, la sujeción del obligado era redimible, estaba destinada a cesar cuando la expectativa del acreedor se viera satisfecha.

Ciertamente la esclavitud se encontraba proscrita en relación con los ciudadanos romanos y, aun tratándose del ligamen físico en que se expresaron algunas obligaciones como las provenientes del nexum, "en realidad el vínculo que caracteriza dicha situación resulta esencialmente enderezado al cumplimiento 
de una deuda determinada en sus contornos precisos, lo cual demuestra que se halla estructuralmente configurada de manera diversa respecto a las formas de manifestación de la potestad", pues en últimas se orientaba al cumplimiento de una deuda determinada y, por ende, su destino natural era la disolución del vínculo.

La importancia de la preservación de este rasgo constitutivo del concepto de obligación romana, que trascendió hasta nuestros días, se pone en evidencia con mucha fuerza en el derecho contemporáneo , en el que una considerable cantidad de obligaciones pretenden desconocerlo mediante subterfugios, traducibles en abusos, que dan lugar a que se pacten obligaciones en condiciones tan gravosas para el deudor, que terminan en la práctica por hacer imposible la disolución del vínculo, erigiéndose así en una nueva forma de esclavitud .

\section{D) La existencia de equilibrio entre la tutela de la satisfacción del crédito y la protección de la condición del deudor}

Alrededor de la satisfacción de los intereses de las partes ligadas al vínculo obligacional, los juristas romanos otorgaron tutelas que protegen las posiciones tanto del deudor como del acreedor. Así, por ejemplo, medidas tendientes a enervar los actos fraudulentos del deudor en desmedro de su propio patrimonio, tales como las restituciones in integrum concedidas por el pretor, o la nulidad de los actos de disposición mediante la acción revocatoria o Pauliana, todo lo cual tenía como efecto proteger los intereses del acreedor, en el marco del carácter vinculante de la obligación.

De otra parte, el vínculo obligacional no estaba desprovisto de las consideraciones propias de la humanitas, de suerte que la facultad de ejecución del acreedor no era absoluta, pues se concedían en favor del deudor el beneficiumcompetentiae que impedía al acreedor llevar acabo la ejecución de la obligación incumplida hasta el punto de dejar al deudor en situación de ruina; a estas tutelas se agregan, entre otras, la propias del favor debitoris, la solidaridad manifiesta en un iusquodammodofraternitatis (D. 17,2,63) y los límites de la responsabilidad.

Bajo este contexto, el proceso de armonización del derecho latinoamericano de obligaciones se ha venido adelantando a la luz de las enseñanzas del método y de los valores del derecho romano.

A este respecto cabe señalar que el Grupo para la Armonización del derecho en América Latina (Gadal) del que forman parte un nutrido grupo de juristas latinoamericanos, ${ }^{47}$ ha retomado el trabajo de armonización del derecho latinoamericano de obligaciones, originado en la iniciativa del profesor Sandro Schipani, a fin elaborar un código de principios que concilie las discordancias y se fortalezca en las semejanzas del derecho latinoamericano alrededor de los consensos de la común herencia del derecho romano.

\section{Conclusión}

Bajo este entendimiento, los retos que impone la globalización en nuestro contexto, podrán ser afrontados sobre la base de un sistema abierto de fuentes, cuyas directrices se centren en el consenso alrededor de los principia iuris del derecho romano, en su valor persuasivo, sopesados a la luz del método de razonar de sus juristas, en el que se reconozcan las diferencias y se valoricen la variedad de matices que revisten los intereses de los diversos participantes; todo lo cual en punto al concepto de 'obligación' nos otorga argumentos para construir una categoría que refleje una concepción esencialmente humana de la misma y, por ende, alredor de la cual se susciten mayores consensos, en cuanto refleja una propia identidad no solo latinoamericana sino una identidad del entero sistema romanista, que nos permite dialogar 47 Sobre la formación, actividades y resultados del grupo para la armonización del derecho en América Latina véase, también en portugués: www.
gadal@uexternado.edu.com. 
con mayor entendimiento con los ordenamientos que no sólo en Europa, en Rusia, en oriente, e incluso en algunas regiones de Norteamérica, han abrevado de esta tradición común o la han elegido por encontrar en ella unos valores más consonantes con su propia manera de comprender todo el fenómeno del derecho de obligaciones. Lo cual a la vez nos permitiría entender las verdaderas diferencias que subsisten con otros sistemas, los caminos de acercamiento con otras tradiciones y los elementos que justificarían la necesidad de una resistencia que impida la fractura de los valores esenciales a la propia tradición jurídica, valorada a la luz de las exigencias contemporáneas.

\section{Referencias}

ALEXY, Robert. Teoría del discurso y derechos humanos. Bogotá: Universidad Externado, 2005. BOBBIO, Norberto. L'etá dei diritti. Torino: Einaudi, 1990.

CATALANO, P. Diritto e persone. Studi su origine e attualità del sistema romano I. Torino: Giappichelli, 1990.

CERULLARE, Mariateresa. "Locus e ius". Observaciones sobre espacio y sistema a la luz del derecho romano. Revista de Derecho Privado, Bogotá, Universidad Externado de Colombia, v. 16, 2009.

CHAMIE, J.F. Sentido actual de los principios generales y armonización del derecho latinoamericano en Sistema jurídico romanista y Subsistema Jurídico Latinoamericano. Liberdiscipulorum para el profesor Sandro Schipani. Bogotá: Universidad Externado, 2013.

CORTÉS, Edgar. Fluidez y certeza del derecho. ¿Hacia un sistema abierto de fuentes? En: El derecho en el contexto de la globalización. Bogotá: Externado, 2007.

FIORI, R. Homo sacer. Napoli: JoveneEditore, 1996;

GALLO, Filippo. Aspetti peculiari e qualificanti della produzione del diritto nell'esperienza romana. Rivista di Diritto romano, v. IV, 2004.

GALLO, Filippo. Sulla definizione Celsina del diritto. En SDHI, 53, 1987.

GROSSO, G. Lezioni di storia del diritto romano. 5. ed. Giappichelli: Torino, 1965.

GROSSO, G. Riflessioni su 'ius civile', 'ius gentium', 'ius honorarium' nella dialettica fra tecnicismotradizionalismo giuridico e adeguazione allo sviluppo economico e sociale in Roma. En: Studi in memoria di Guido Donatuti. v. I. Milán: Cisalpino-La Goliardica, 1973.

HABERMAS, Jürgen. Teoría de la acción comunicativa I. Racionalidad de la acción y racionalización social. Aguilar, Santillana, Altea-Taurus, Alfaguara, Madrid, Bogotá, D-F. México, Buenos Aires, 1999.

HINESTROSA, Fernando. Codici, Università, Scienza Giuridica: una strategia per l'unificazione del diritto in America Latina. Roma e America. Diritto Romano Comune. Rivista di diritto dell'integrazione e unificazione del diritto in Europa e in America Latina. Modena: MucchiEditore. Número 1, 1996.

HINESTROSA, Fernando. De los principios generales del derecho a los principios generales del contrato. Revue de Droit Uniforme. v. III, n. 2/3. (a la memoria de Malcom Evans). Roma: UNIDROIT, 1998.

JAYME, Erik. Identité culturelle et intégration: le droit international privé postmoderne. Recueil des Cours de l'Academie de Droit Internacional de la Haye, Nijhoff, Haye, 1995, v. II.

LOMBARDI, Gabrio. Sul concetto di “iusgentium”. Roma: Istituto di Diritto romano, 1947.

LÓPEZ MEDINA, D. E. Interpretación constitucional. 3. ed. Escuela Rodrigo Lara Bonilla, sept. 2011.

LOS MOZOS, José Luis de. Principios generales del derecho. Roma e America. Diritto Romano Comune. Rivista di diritto dell'integrazione e unificazione del diritto in Europa e in America Latina. Modena: MucchiEditore. n. 1, 1996. 
MARQUES, Cláudia Lima. Diálogo das fontes como método da nova teoría geral do direito. En: Diálogo Das Fontes: Do conflito à coordenação de normas do direito brasileiro. São Paulo: Revista dos Tribunais, 2012.

MARTINS-COSTA, Judith. O Direito Privado como um "sistema em construção": as cláusulas gerais no Projeto do Código Civil brasileiro. Jus Navigandi, Teresina, ano 4, n. 41, mayo. 2000.

MAZEAUD, Henri. Métodos de trabajo. Bogotá: Universidad Externado de Colombia, 2012.

REALE, Miguel. Visão geral do Projeto de Código Civil. Consultado en: < http://www.miguelreale.com. br/.>. Accesso el: 10 jan. 2014.

RODOTÀ, Stefano. Il diritto di avere diritti: Laterza, 2012.

SAENZ, A. Castro. Cicerón y la jurisprudencia romana: Tirant lo Blanch: Valencia, 2010.

SALGADO, Catalina. Breves reflexiones sobre la interacción entre ordenamiento y sistema del iusromanum, en Sistema jurídico romanista y Subsistema Jurídico Latinoamericano. Liberdiscipulorum para el profesor Sandro Schipani. Bogotá: Universidad Externado, 2013.

SALGADO, Catalina. Riconoscimento del sistema, interpretazione sistematica, armonizazione e unificazione del diritto, en Roma e America Diritto romano comune. Cedam-Externado, Modena Bogotá, v. 24, 2007.

SALGADO, Catalina. Trenta anni di dialogo con i giuristi latinoamericani. En: Roma e America. Diritto Romano Comune. Rivista di diritto dell'integrazione e unificazione del diritto in Europa e in America Latina, Modena: MucchiEditore, n. 21, 2006.

SCHIPANI, Sandro. La codificazione del diritto romano comune. Torino: Giappichelli, 1996.

TALAMANCA, M. 'Ius gentium' da Adriano ai Severi. En: AA. VV. La codificazione del diritto dall'antico al moderno. Nápoles: Editoriale Científica, 1998.

VACCA, Letizia. La giurisprudenza nel sistema delle fonti del diritto romano. Corso di lezione. Segunda edición. Torino: Giappichelli, 2012.

VECA, Salvatore. El paradigma de las teorías de la justicia. En: RODRÍGUEZ, Manuel Cruz; VATTIMO, Gianni (Coord.). Pensar en el siglo. Taurus: 1999.

VILLARREAL, Martha Lucía Neme. La buena fe en el derecho romano. Extensión del deber de actuar de buena fe en materia contractual. Bogotá: Universidad Externado de Colombia, Centro di Studi Giuridici Latinoamericani Università "TorVergata” CNR Roma Italia. 2010.

VILLARREAL, Martha Lucía Neme. Pacta suntservanda y rebus sic stantibus: tensiones entre los principios de buena fe y autonomía contractual. México: Universidad Panamericana, Enero 2015.

VILLARREAL, Martha Lucía Neme. Principios, cláusulas generales y estándares como orientadores del sistema jurídico, en: Estudios de Derecho Civil en Memoria de Fernando Hinestrosa. Bogotá: Externado de Colombia, 2014.

ZAGREBELSKY, Gustavo. II diritto mite. Torino: Enaudi Contemporanea, 1992.

ZIMMERMANN, Reinhard. Derecho romano, derecho contemporáneo, derecho europeo. Bogotá: Universidad Externado de Colombia, 2010.

Recebido em: 28/06/2017

Aprovado em: 10/07/2017 